\title{
Effect of Rock Fracture Filling on Mode I and II Fracture Toughness
}

\author{
H.R. Nejati ${ }^{1 *}$, M.J. Azinfar ${ }^{2}$ \\ 1- Rock Mechanics Division, School of Engineering, Tarbiat Modares University, Tehran, Iran \\ 2- Dept. of Mining Engineering, University of Sistan and Baluchestan, Iran
}

* Corresponding Author: h.nejati@modares.ac.ir

(Received: October 2016, Accepted: March 2019)

\begin{tabular}{|c|c|}
\hline Keywords & Abstract \\
\hline Fracture Toughness & $\begin{array}{l}\text { This paper focuses on some fracture toughness tests performed on } \\
\text { the pre-cracked Brazilian specimens of rock-like materials. Also the }\end{array}$ \\
\hline Fracture Filling & effect of rock fracture filling on the fracture toughness was \\
\hline Brazilian Test & considered experimentally. Fracture toughness is a key parameter \\
\hline CSCBD Specimen & $\begin{array}{l}\text { for studying the crack propagation and fragmentation processes in } \\
\text { rock structures. Fracture mechanics is an applicable tool to improve }\end{array}$ \\
\hline Rock-Like Material & $\begin{array}{l}\text { the mechanical performance of materials and components. It is a } \\
\text { comparatively general phenomenon that rock fractures are } \\
\text { naturally filled with gouging material, but the impact of fillings on }\end{array}$ \\
\hline rock fracture to & been considered precisely. In the present study, an experime \\
\hline $\begin{array}{l}\text { investigation was } \\
\text { and fracture toug }\end{array}$ & $\begin{array}{l}\text { effect of rock fracture fillings on the crack propagation mech } \\
\text { specimens. For this purpose, several molds are used for prepa }\end{array}$ \\
\hline of $\mathrm{Br}_{\mathrm{c}}$ & en \\
\hline compression load & nin in different directions re \\
\hline$f(1)-$ & ess \\
\hline 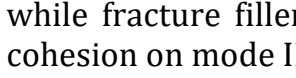 & \\
\hline
\end{tabular}

\section{INTRODUCTION}

The ability of rock to resist fracturing and propagation of pre-existing cracks was introduced as rock fracture toughness or critical Stress Intensity Factor (SIF). Rock fracture toughness is an intrinsic rock property that is used as an index for fragmentation processes such as rock cutting, hydraulic fracturing, explosive modeling etc. [1-3] Numerous experimental and numerical researches have been developed for assessing rock fracture toughness in different conditions of fracture and loading.

It has been reported that fracture toughness of rocks increases with increasing confining pressure [4-6].

Khan and Al-Shayea investigated the effect of specimen geometry and testing method on mixed mode I/II fracture toughness. They found that specimen diameter and crack type have a substantial influence on the measured fracture toughness [7].

Al-Shayea investigated the trajectories of crack under mixed mode I/II loading in limestone with high brittleness under CSCBD specimen. Furthermore, the effect of confining pressure and temperature on crack initiation and propagation was also studied by him [8].

Ke et al. presented a systematic procedure for determining fracture toughness of an anisotropic marble using the diametric compression test (Brazilian test) with a central crack on the disks. They developed a new fracture criterion to predict pure mode I, pure mode II, or mixed mode (I/II) fracture toughness of the anisotropic marble [3].

A new cubic element formulation of the displacement discontinuity method using three special crack tip elements for crack analysis has been developed by Fatehi Marji et al. This analyses 
are performed based on mixed mode I/II stress intensity factor and LEFM concept [9].

Ayatollahi and Aliha used Brazilian disk specimen to calculate mixed mode (I/II) fracture toughness of rock materials. They applied a generalized MTS criterion for evaluating the fracture toughness of rock materials under mixed mode I/II loading [10].

The crack propagation modeling in rock-like Brazilian containing three parallel cracks was investigated by Haeri el al. They confirmed that wing cracks are initiated at the first stage of loading and propagated toward the direction of compressive line load [11].

Sabri et al. evaluated the effect of particle size on fracture toughness and failure mechanism of Rocks and showed that fracture toughness of specimens has a nonlinear relation with grain size. Specimen with medium grain size ( $3 \mathrm{~mm}$ ) has the maximum mode I fracture toughness compared to the specimens with small $(1 \mathrm{~mm})$ and large (5 $\mathrm{mm}$ ) grain size particles [12].

The effect of loading rate on failure mechanism of CSCBD specimens was considered using numerical modeling by Imani et al. in a wide range of strain rates. They showed that the effects of central pre-crack in the failure pattern and strength of CSCBD specimen decrease with increasing strain rate [13].

Fractures of rock structures are naturally filled with filling materials and it is expected that the fillers influence on the stress intensity factor of crack tips and consequently, affect rock fracture toughness. As mentioned before, although filled fractures are abundant in the natural rock structures, impact of fillings on rock fracture toughness has not been considered precisely.

Previous research mostly focused on open cracks and closed cracks without fillings, while cracks in rock called joint, are often filled with sands, ooze and etc. The filling can be naturally formed or manually filled during the construction process such as grouting and shotcrete. The present research intends to plan an experimental study for the evaluation of fracture filling influence on fracture toughness of rock-like materials.

Zhuang et al. investigated the crack propagation behavior of the filled and unfilled crack and compared by testing rock-like specimens subjected to uniaxial compression. A qualitative analysis of the crack propagation paths is described where crack is classified into four types, namely the original, secondary, wing and anti-wing cracks. The experiments indicated the crack initiation time, initiation location and propagation behavior are different between filled and unfilled joints. The experimental results also showed that the most important difference between unfilled and filled cracks is the crack initiation stress and initiation angle. The initiation stress ratios of the first crack for unfilled crack are higher than the filled crack with respect to the same original crack inclination angle. For specimens with filled crack, the wing crack and anti-wing crack initiation are at lower angle than for unfilled crack [14].

\section{ROCK FRACTURE TOUGHNESS}

Several experimental testing methods have been developed for determination of rock fracture toughness for the three fundamental fracture modes. Short rod specimen method (SR), Chevron bend specimen method (CB) and Cracked Chevron Notched Brazilian Disk method (CCNBD) are those proposed by ISRM to determine the pure fracture toughness in mode I $[15,16]$.

Central Straight-through Crack Brazilian Disk (CSCBD) method is another testing method that is used to determine rock fracture toughness. In addition to the pure fracture toughness in mode I, CSCBD can be used to determine pure fracture toughness in mode II and Mixed mode I-II. This is obtained by diametrical loading of pre-existing cracked disks positioned at different crack orientation $\beta$ angles (Fig. 1).

Atkinson et al., proposed an analytical expression to calculate the fracture toughness of material using CSCBD specimen as [17];

$$
\begin{aligned}
& K_{I}=\frac{P \sqrt{a}}{\sqrt{\pi} R B} N_{I} \\
& K_{I I}=\frac{P \sqrt{a}}{\sqrt{\pi} R B} N_{I I}
\end{aligned}
$$

Where $K_{I}\left(\mathrm{~Pa} \cdot \mathrm{m}^{0.5}\right)$ is mode I stress intensity factor, $K_{I I}\left(\mathrm{~Pa} \cdot \mathrm{m}^{0.5}\right)$ is mode II stress intensity factor, $\mathrm{R}(\mathrm{m})$ is the radius of Brazilian disk, B (m) is thickness of the disk, $\mathrm{P}(\mathrm{N})$ is compressive load at failure, a (m) is half crack length, $N_{I}$ and $N_{I I}$ are non-dimensional coefficients which depend on ratio of half crack to radius $(a / R)$ and crack orientation angles with respect to the diametrical load. Determination of the exact values of $N_{I}$ and $N_{I I}$ is difficult as complicated functions of $a / R$ and $\beta$ are to be worked out. Atkinson et al. 
proposed the following equations for relatively small crack length $(a / R \leq 0.3)$ [17]:

$$
\begin{aligned}
& N_{I}=1-4 \sin ^{2} \beta+4 \sin ^{2} \beta\left(1-4 \cos ^{2} \beta\right)\left(\frac{a}{R}\right)^{2} \\
& N_{I I}=\left[2+\left(8 \cos ^{2} \beta-5\right)\left(\frac{a}{R}\right)^{2}\right] \sin 2 \beta
\end{aligned}
$$

The mechanism of crack propagation in brittle solids has been studied by comprehensive experimental and numerical studies in recent years. This mechanism is a complicated process and further research may be devoted to investigate the crack propagation, crack coalescence in the bridge area, and final breakage paths of the rocks and rock-like materials under compressive line loading. Brazilian disk-type specimens of rock-like material can be effectively used to accomplish these investigations [18].

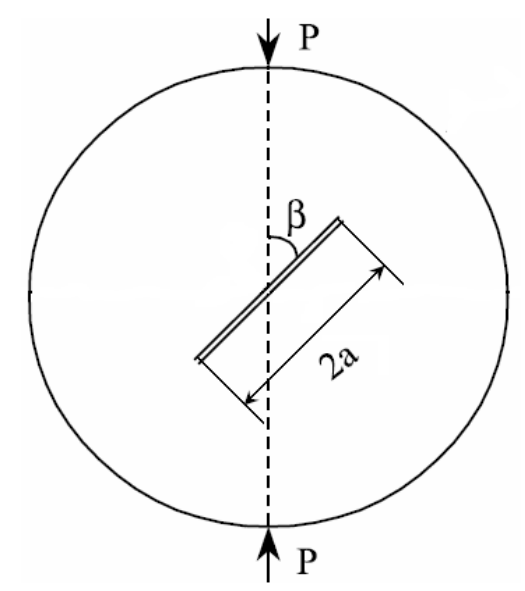

Figure 1. Schematic view of CSCBD specimen for determination of Mode I, II and mixed mode I-II fracture toughness.

\section{EXPERIMENTAL INVESTIGATION}

The ingredients used for physical modeling rocklike material with low brittleness consisted of Portland Pozzolana cement, plaster, and water mixed by proper ratios. Molds were used for the preparation of the required specimens. The mixed ratios and mechanical properties of the used mortar together are presented in Table 1.

Rock crack propagation has been considered experimentally in many studies so far. One of the most important challenges in studying rock crack propagation is preparation of similar specimens in strength, homogeneity, isotropy and structural size. Heterogeneity and anisotropy have a significant effect on the crack propagation and fracture toughness of rocks [19, 20, 3]. Furthermore, creation of central crack in the rock specimen may be concomitant with inconvenience and undesirable result. In this study, artificial material is used to prepare some homogen, isotropic, and unique structural size specimens. Then, crack propagation is considered in CSCBD specimens of rock-like material with $103 \mathrm{~mm}$ diameter and a central crack with $30 \mathrm{~mm}$ length. Fig. 2 shows variation of $N_{I}$ and $N_{I I}$ with inclination angle of central crack respect to the loading direction, in CSCBD specimen. As depicted in Fig. 2, pure tensile loading is achieved only at $\beta=0^{\circ}$ whereas pure mode II loading is obtained at $\beta=27^{\circ}$. Hence, for the evaluation of the effect of fillers on mode I and II fracture toughness experimental tests were performed in the two inclination angles.

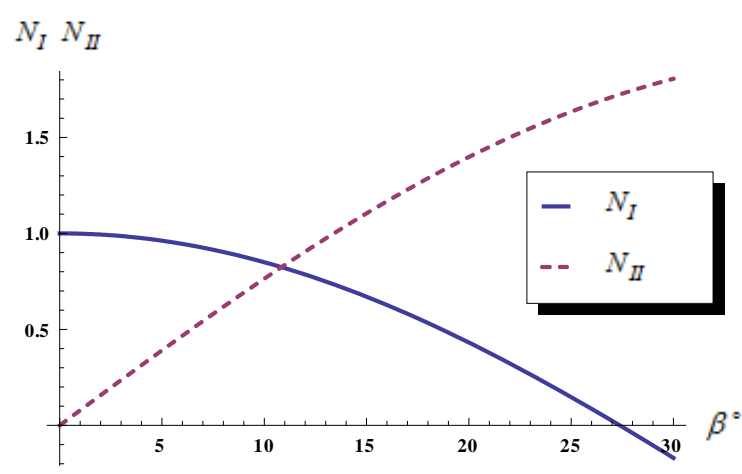

Figure 2. variation of NI and NII with inclination of central crack in CSCBD specimen.

Table 1. Ratio of ingredients and mechanical properties of the prepared specimens.

\begin{tabular}{cccccc}
\hline & Ingredients ratio (\%) & & Mechanical Properties \\
\hline Plaster & P.P. cement & Water & Compressive & Tensile Strength & Density (Kg/m3) \\
30 & 30 & 40 & strength (MPa) & (MPa) & 1 \\
\hline
\end{tabular}

\subsection{Material and Specimen Preparation}

A proper ratio of Portland Pozzolana cement (PP cement), plaster, and water are mixed and some polyethylene frames are used for preparation of the required specimens (Table 1). Also, three different ratios of ingredients have been used for preparation of three model materials of fillers. The mixed ratios and 
mechanical properties of the used mortar together are presented in Table 2. Totally 36 CSCBD specimens were prepared using mortar type 2 and the central crack of 24 samples are filled with the three mortar types.

\subsection{Testing Apparatus}

An experimental setup including a servoelectric testing machine with a data acquisition system (Fig. 3) are employed to perform fracture toughness tests on CSCBD specimens. The testing machine that is used for these series of tests is strain control and the loading rate was kept at 0.3 $\mathrm{mm} / \mathrm{min}$.

It has been shown that two failure modes (tensile and fracture toughness) are observable in CSCBD specimen based on the central crack length and its orientation with loading direction $[8,21]$. However, for specimens under study, with ratio of $a / R=0.29$, central crack orientations of zero and 27 degree only fracture toughness failure mode occurrs. Fig. 4 illustrates that modes I and II crack propagation path in CSCBD specimens have not been influenced by fillers and the specimens failed in fracture toughness mode.

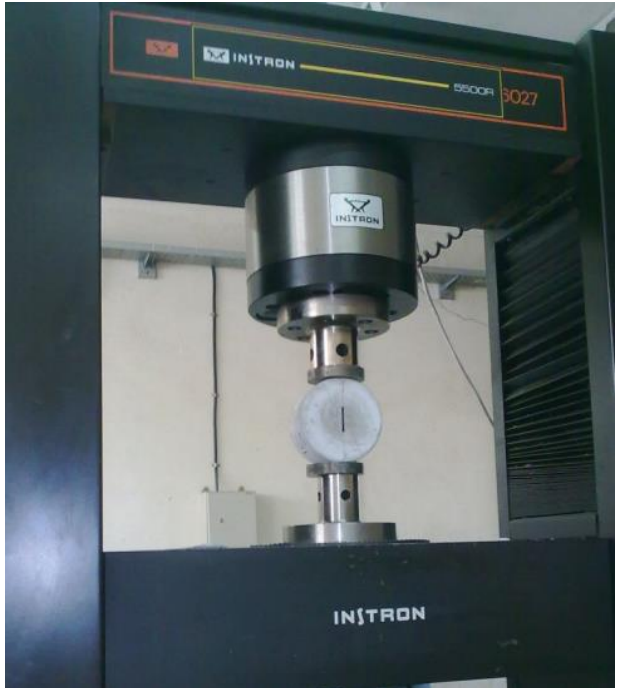

Figure 3. servo-electric load frame and CSCBD specimen.

Although fracture filler has no influence on the failure mode of CSCBD specimens, it affects, as a result, the failure load of specimen and fracture toughness. Results of experimental tests are listed in Table 3.

Table 2. Selected mortars and their proportions for preparation of fillers.

\begin{tabular}{|c|c|c|c|c|c|c|c|c|}
\hline \multicolumn{5}{|c|}{ Ingredients ratio (\%) } & \multicolumn{4}{|c|}{ Mechanical properties } \\
\hline Mortar & Plaster & PP Cement & Water & Clay & $C$ & $\varphi$ & $\sigma_{c}$ & $\sigma_{t}$ \\
\hline & & & & & $\mathrm{MPa}$ & Degree & $\mathrm{MPa}$ & MPa \\
\hline Type 1 & 25 & 15 & 35 & 25 & 1.4 & 38 & 5.9 & 0.89 \\
\hline Type 2 & 31.5 & 31.5 & 37 & - & 2.8 & 39 & 12 & 3.4 \\
\hline Type 3 & $60(\# 50)$ & 5 & 35 & - & 4.4 & 41 & 19.5 & 1.57 \\
\hline
\end{tabular}

Table 3. Selected mortars and their proportions in the sample materials.

\begin{tabular}{|c|c|c|c|c|c|c|}
\hline Loading mode & & Mode I & & & Mode II & \\
\hline Filling Type & $\begin{array}{c}\text { Number of } \\
\text { tests }\end{array}$ & $\begin{array}{c}\text { Ave. failure } \\
\text { Load (KN) }\end{array}$ & $\begin{array}{c}\text { KIC } \\
\text { MPa.m^^0.5 }\end{array}$ & $\begin{array}{c}\text { Number of } \\
\text { tests }\end{array}$ & $\begin{array}{c}\text { Ave. failure } \\
\text { Load (KN) }\end{array}$ & $\begin{array}{c}\text { KIIC } \\
\text { MPa.m^ }^{\wedge} 0.5\end{array}$ \\
\hline No filler & 3 & 3.67 & 0.20 & 3 & 4.59 & 0.43 \\
\hline Mortar Type 1 & 3 & 4.52 & 0.26 & 4 & 5.32 & 0.50 \\
\hline Mortar Type 2 & 3 & 5.01 & 0.26 & 3 & 5.61 & 0.53 \\
\hline Mortar Type 3 & 3 & 5.25 & 0.30 & 4 & 5.87 & 0.6 \\
\hline
\end{tabular}

As shown in Table 2, the existence of filler increases fracture toughness and different fillers induce different fracture toughness for tested samples. Fig. $5 \mathrm{a}$ and $\mathrm{b}$ depict variation of fracture toughness with cohesion and tensile strength of fillers. It is inferred from Fig. 5 that filler cohesion compared to tensile strength of filler has more influence on the fracture toughness. It should be noted that interface properties of specimen and filler influence the fracture toughness, but in this research, only variation of facture toughness with filler properties has been considered.

Among the filler properties, cohesion has a great influence on the fracture toughness of prepared specimens. Furthermore, the impact of cohesion on mode II fracture toughness is more than its impact on mode I. 


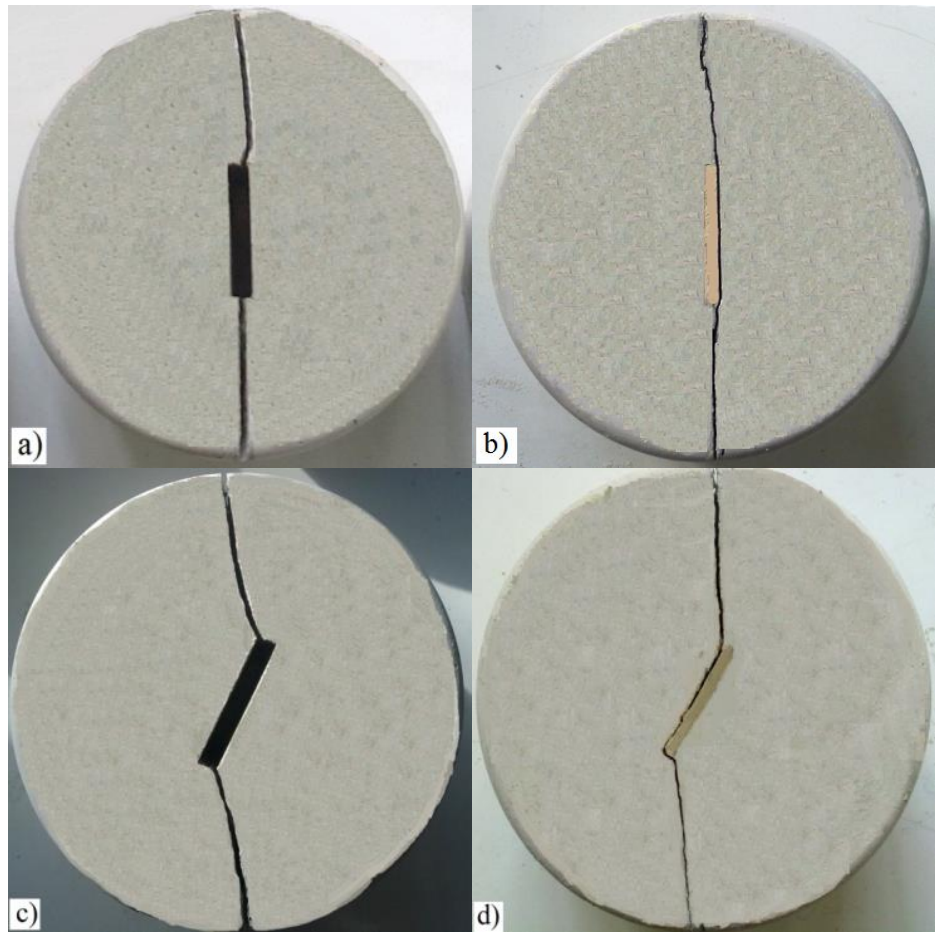

Figure 4. Results of experimental modeling, (a) mode I fracture without filler, (b) mode I fracture with filler (c) mode II fracture without filler and (d) mode II fracture with filler.
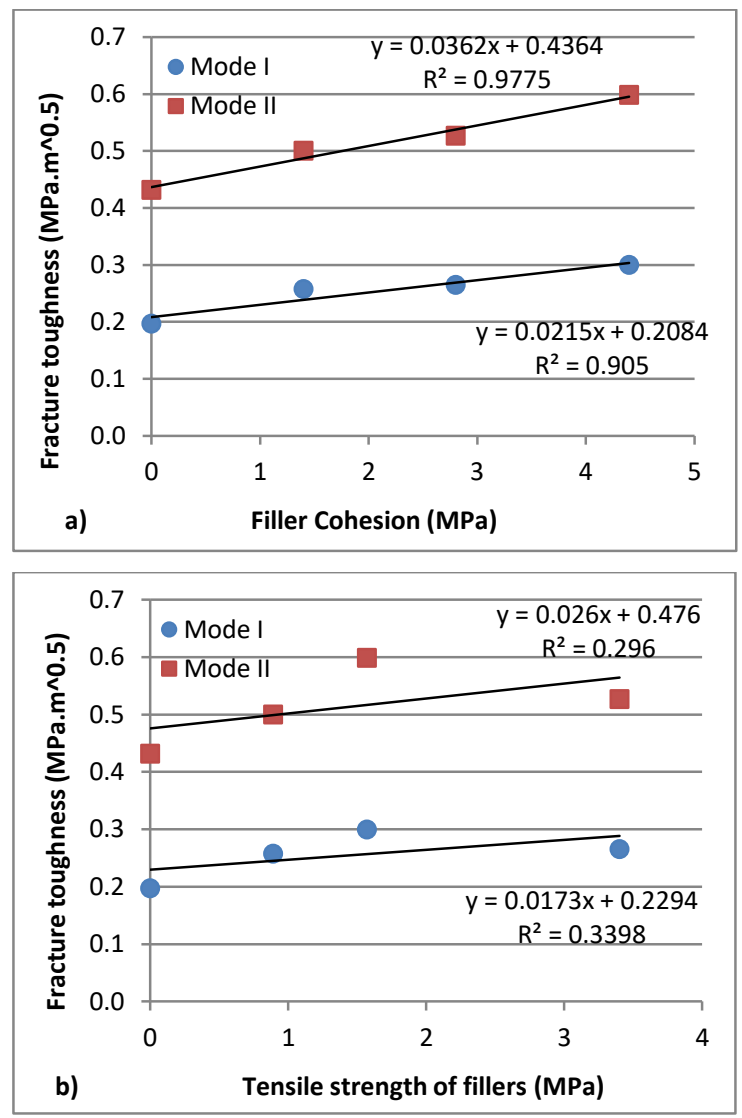

Figure 5. variation of fracture toughness with (a) cohesion and (b) tensile strength of fillers.
Based on the performed experimental tests, fracture fillings can cause an increment in mode I fracture toughness (KIC) up to $50 \%$, while they only provide a $40 \%$ increase in mode II fracture toughness (KIIC).

\section{STRESS DISTRIBUTION}

It is obvious that central crack influences the stress distribution in specimen. When there is a crack in the center of a disk, stress is concentrated at the crack tip and the distributed stress is a function of the crack length as well as its orientation with respect to the loading direction [8]. In this section, a numerical modeling is made to investigate the effect of filling on the stress distribution at the specimen. As shown in Fig. 6, although there is not a significant stress concentration at the tip of the filled crack, stress distribution is influenced by the stiffness and strength of the filling. Fig. $6 a$ and $b$ illustrate contours of differential principal stress at the "uncracked" and "pre-cracked and filled" specimen, respectively. 


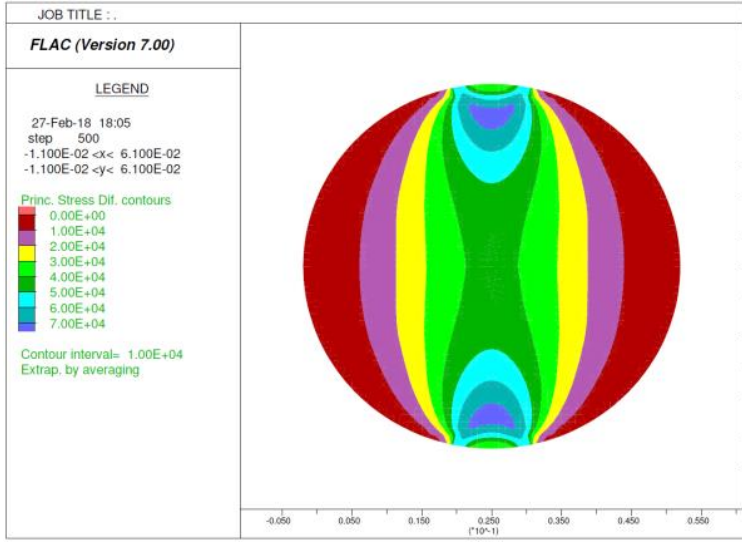

a

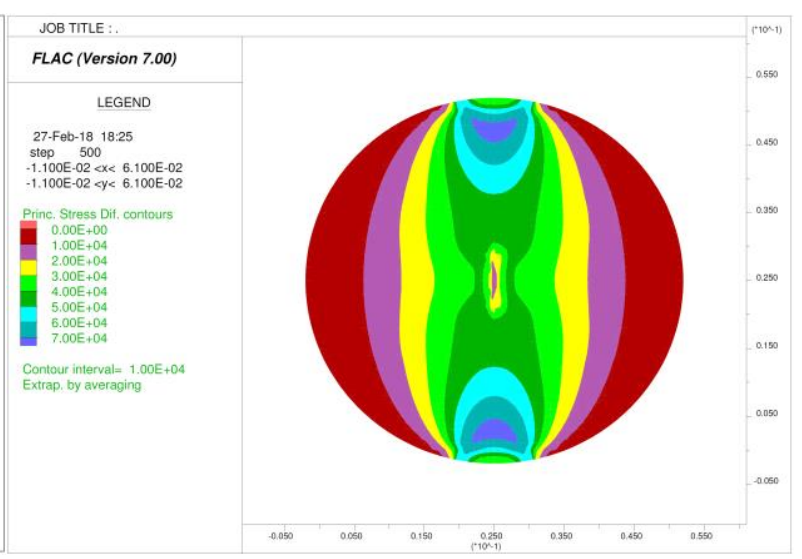

$\mathbf{b}$

Figure 6. contours of differential principal stress at (a) "uncracked" and (b) "pre-cracked and filled" specimens.

\section{CONCLUSIONS}

In the present study, the effect of rock fracture fillers on both tensile and shear fracture mode has been considered experimentally. Results of laboratory investigations are summarized as follow:

Failure modes of CSCBD specimen in pure tensile and shear loading are fracture toughness failure mode and fracture filler has no influence on the failure mode of CSCBD specimens.

The existence of fillers increases fracture toughness and different fillers induce different fracture toughness for tested samples.

Intrinsic cohesion of fillers, compared to tensile strength, has more influence on the fracture toughness of the studies specimens.

The impact of filler cohesion on mode II fracture toughness is more than its impact on mode I fracture toughness.

Although there is not a significant stress concentration at the tip of the filled crack, stress distribution is influenced by the stiffness and strength of the filling.

\section{REFERENCES}

[1] Sun Z, Ouchterlony F (1986) Fracture toughness of Stripa granite cores. Int J Rock Mech Min Sci Geomech Abstr 23(6):399-409.

[2] Whittaker BN, Singh RN, Sun G (1992) Rock fracture mechanics principles, design and applications, developments in geotechnical engineering. Elsevier, Amsterdam

[3] Ke CC, Chen CS, Tu CH (2008) Determination of fracture toughness of anisotropic rocks by boundary element method. Rock Mech Rock Engng 41(4):509-538

[4] Schmidt, R.A. and Huddle, C.W. (1977), Effect of confining pressure on fracture toughness of Indiana limestone, Int. J. Rock. Mech. Min. Sci. and Geomech. Abstr. 14, 289-293.

[5] Abou-Sayed, A.S. (1978), An experimental technique for measuring the fracture toughness of rock under downhole stress condition, VDIBerichte 313, 819-824.

[6] Funatsu, T., Seto, T., Shimada, H., Matsui, K. and Kuruppu, M. (2004), Combined effects of increasing temperature and confining pressure on the fracture toughness of clay bearing rocks, Int. J. of Rock. Mech. and Min. Sci. 41, 927-938.

[7] Khan K, Al-Shayea NA (2000) Effect of specimen geometry and testing method on mixed mode I-II fracture toughness of a limestone rock from Saudi Arabia. Rock Mech Rock Engng 33 (3):179-206

[8] Al-Shayea NA (2005) Crack propagation trajectories for rocks under mixed mode I-II fracture. Eng Geol 81:84-97.

[9] Haeri, H., Shahriar, K., Marji, M. F., \& Moarefvand, P. (2014). Investigation of fracturing process of rock-like Brazilian disks containing three parallel cracks under compressive line loading. Strength of Materials, 46(3), 404-416.

[10] Ayatollahi MR, Aliha MRM (2008) On the use of Brazilian disk specimen for calculating mixed mode I-II fracture toughness of rock materials. Eng Fract Mech 75:4631-4641.

[11] Fatehi Marji, M., Hosseini-Nasab, H., \& Kohsary, A. H. (2007). A new cubic element formulation of the displacement discontinuity method using three special crack tip elements for crack analysis. JP J. Solids Struct, 1(1), 61-91. 
[12] Sabri, M., Ghazvinian, A., \& Nejati, H. R. (2016). Effect of particle size heterogeneity on fracture toughness and failure mechanism of rocks. International Journal of Rock Mechanics and Mining Sciences, 81, 79-85.

[13] Imani, M., Nejati, H. R., \& Goshtasbi, K. (2017). Dynamic response and failure mechanism of Brazilian disk specimens at high strain rate. Soil Dynamics and Earthquake Engineering, 100, 261269.

[14] Zhuang, X., Chun, J., \& Zhu, H. (2014). A comparative study on unfilled and filled crack propagation for rock-like brittle material. Theoretical and Applied Fracture Mechanics, 72, 110-120.

[15] Ouchterlony F (1988) Suggested methods for determining the fracture toughness of rock. Int J Rock Mech Min Sci 25(2):71-96

[16] Fowell RJ (1995) Suggested method for determining mode I fracture toughness using cracked chevron notched Brazilian disk (CCNBD) specimen. Int J Rock Mech Min Sci Geomech Abstr 32:57-64

[17] Atkinson C, Smelser RE, Sanchez J (1982) Combined mode fracture via the cracked Brazilian disk. Int J Fracture 18:279-291

[18] Haeri, H., Khaloo, A., \& Fatehi Marji, M., (2015). Experimental and numerical analysis of Brazilian discs with multiple parallel cracks. Arabian Journal of Geosciences, 8(8), 5897-5908.

[19] Chen C, Pan E, Amadei B (1998) Fracture mechanics analysis of cracked discs of anisotropic rock using the boundary element method. Int J Rock Mech Min Sci 35(No. 2):195-218

[20] Nasseri MHB, Mohanty B (2008) Fracture toughness anisotropy in granitic rocks. Int J Rock Mech Min Sci 45:167-193

[21] Ghazvinian, A., Nejati, H. R., Sarfarazi, V., \& Hadei, M. R. (2013). Mixed mode crack propagation in low brittle rock-like materials. Arabian Journal of Geosciences, 6(11), 4435-4444. 